\title{
Projections of Energy Use and Carbon Emissions for Bangkok, Thailand
}

\author{
Aumnad Phdungsilp*
}

\author{
Engineering Management Graduate Program, College of Innovative Technology and Engineering, Dhurakij \\ Pundit University, Bangkok, Thailand
}

\begin{abstract}
Cities around the world have developed innovative plans and strategies to reduce rampant and uncontrolled energy use and $\mathrm{CO}_{2}$ emissions. It is not surprising that many cities have adopted long-term emission reduction goals. However, a detailed analysis of energy use and the resulting carbon emissions are rare in developing countries. This paper presents historical trends of energy demand and energy-related $\mathrm{CO}_{2}$ emissions for Bangkok, Thailand. The $\mathrm{CO}_{2}$ emissions account for the use of fossil fuels only. It also presents the projections of energy use and $\mathrm{CO}_{2}$ emissions from 2010 to 2050. Using a bottom-up energy model and scenario analysis, the paper employs a Long-range Energy Alternative Planning (LEAP) system to simulate four sectors in Bangkok. The results identified by the BAU (business-asusual) scenario indicate that total energy is expected to reach 54,560 kilotonne of oil equivalent (ktoe) with 191 million tonne $\mathrm{CO}_{2}\left(\mathrm{Mt}_{-} \mathrm{CO}_{2}\right)$ by 2050 . Under the alternative scenario, if all policy interventions are implemented simultaneously, the potential for energy-savings and reduced $\mathrm{CO}_{2}$ emissions in 2050 are estimated to be 32,120 ktoe and 106.19 Mt$\mathrm{CO}_{2}$. Other international cities may wish to apply the strategies and analytical approaches presented in this paper for developing appropriate policies and measures in their own jurisdictions.
\end{abstract}

Keywords: $\mathrm{CO}_{2}$ emissions, Energy-savings, Energy modeling, Low-carbon city, Scenario analysis.

\section{INTRODUCTION}

Urbanization is a key driver from the energy and climate perspective. Cities across the world have developed strategies for reduction of energy demand, as well as $\mathrm{CO}_{2}$ emissions. These strategies are referred to as low carbon development strategies. Many cities have relied on fossil fuels and have desired to move towards low carbon development pathways. In addition, some cities have been influenced by international agreements, for example the Paris Agreement of UNFCCC (United Nations Framework Convention on Climate Change) and the UN (United Nations) Sustainable Development Goals.

Bangkok is an economic-driven city in Thailand, and is governed by the Bangkok Metropolitan Administration (BMA). However, national government agencies undertake some energy and climate-related projects in Bangkok, and are responsible for key infrastructures, such as the mass transit systems. The development of a sustainable city needs to understand the past, present, and future pathways, as well as key features, such as energy systems.

It is important to know the size of the challenges ahead and to understand what technological and behavioral changes can be expected to alter the future,

*Address of correspondence to this author at the Engineering Management Graduate Program, College of Innovative Technology and Engineering, Dhurakij Pundit University, Bangkok, Thailand; Tel: +66 (2) 954 7300; Fax: +66(2) 954 7356; E-mail: aumnad@dpu.ac.th

JEL: C53, P18, Q47. and what further changes need to be induced by policy intervention. The paper contributes to an understanding of energy demand, $\mathrm{CO}_{2}$ emissions, and science-based policy formulation.

The paper focuses on commercial energy use and associated $\mathrm{CO}_{2}$ emissions. It estimates past energy use and energy-related $\mathrm{CO}_{2}$ emissions in Bangkok from 1950 to 2010, and outlines future trends of energy demand and energy-related $\mathrm{CO}_{2}$ emissions from 2010 to 2050. Results of the paper can be used to prepare energy and climate strategies for Bangkok.

This paper develops and evaluates policy interventions that explore a range of possible future energy use and energy-related $\mathrm{CO}_{2}$ emissions. The main objectives are to quantify energy demand and $\mathrm{CO}_{2}$ emissions, assess different policy options in a view of "what-if" question in four sectors (such as commercial, industrial, residential, and transportation), and analyze the energy and emission trends from a long term perspective. The results can provide insights to policy-makers in creating feasible and practical energy and climate policies, as well as a path towards a low-carbon society.

The remainder of the paper is as follows. Section 2 presents a review of energy systems modeling that has been used to support energy and climate strategies at the city level. Section 3 describes the methodology, description of policy interventions, and data sources. Section 4 presents the results of the modeling and analysis of the empirical findings. The results deal with 
information about past and future energy demand and $\mathrm{CO}_{2}$ emissions. The paper draws conclusions in section 5 , with a focus on energy demand and $\mathrm{CO}_{2}$ emissions, and mitigation opportunities in each sector.

\section{CITY ENERGY MODELING}

The number of studies on energy use and energyrelated $\mathrm{CO}_{2}$ emissions has been increasing worldwide. City-wide strategies for analyzing the transition to lowcarbon development have been conducted by energy systems modeling in many cities. In the literature, different energy models have been developed over the past two decades. Some models are generic and can be applied elsewhere, but some are models for specific areas.

In addition to the use of energy models, scenario analysis has been used as a method for analyzing a long-term view and attempting to harmonize socioeconomic and environmental goals. Combining energy systems modeling and scenario analysis has become a widely-used approach for exploring possible and plausible future pathways and their implications (Allen et al., 2016). A comprehensive review of different methods and tools for analyzing energy and environmental aspects in city can be found in Phdungsilp (2015), Huang et al. (2015), and Markovic et al. (2011). Recently, some well-known energy models, such as TIMES (Integrated MARKAL-EFOM System), LEAP (Long-range Energy Alternatives Planning system), and EnergyPLAN, have been used to analyze the transition to low-carbon cities (Lind and Espegren, 2017; Yang et al., 2017; Zhao et al., 2017).

Among various energy models, there has been an increased use of the LEAP model in cities around the world over the past decade (Heaps, 2016). In developing countries, the pioneer work of using LEAP for comprehensive city energy modeling was at the University of Cape Town, South Africa. LEAP was used to simulate energy scenarios for Cape Town from 2000 to 2010 (Winkler et al., 2005). The modeling focuses on the implications of policy interventions for potential energy savings, GHG (Greenhouse Gas) emission reductions, and local air pollutants from different sectors. In Thailand, Rinchumpoo (2005) used LEAP to analyze energy and environmental issues of alternative transport scenarios for the Greater Bangkok region in the period 2002 to 2030. However, this work focuses only on the transport sector, while other sectors are not analyzed. Kadian et al., 2007 applied LEAP for modeling total energy use and associated emissions from the household sector in Delhi. The work looks into the policy implications, which can be implemented effectively at the city level for Delhi.

In Bangkok, Phdungsilp (2010) applied LEAP to integrated energy and carbon modeling for low-carbon development. The Bangkok energy model was developed to examine policy interventions, both at the demand and supply sides in four economic sectors, namely residential, commercial, industrial, and transport. The planning period is 2005 to 2025, with 2000 taken as the base year. Peng et al. (2015) applied LEAP to extrapolate energy use, GHG emissions, and urban transportation of Tianjin in China between 2010 and 2040 under four scenarios. Martinez-Jaramillo et al. (2017) used LEAP for assessing the impacts of transport policies in the Medellin Metropolitan Area in Colombia.

In the case of a developed country such as the USA, four energy scenarios for California were developed and analyzed using LEAP. The California model characterized the composition and structure of energy, fuel use, and GHG emissions between 2000 and 2035 (Ghanadan and Koomey, 2005). LEAP was used as a modeling framework to conduct a demanddriven scenario analysis for projecting Seattle's future GHG emissions and analyzing strategies for mitigation scenario (Lazarus et al., 2013).

\section{METHODOLOGY}

\subsection{Historical Analysis}

Historical energy use data back to 1950 were assembled to calculate energy use and energy-related $\mathrm{CO}_{2}$ emission trends over time. There is no disaggregated data for all end-use energy consumption allocated to the end-use sectors. A time series database for petroleum products and electricity was complied. The collected data were the direct amounts of energy consumed. $\mathrm{CO}_{2}$ emissions were calculated using emission factors, as shown in equation (1). Emission factors for petroleum products were calculated based on IPCC (Intergovernmental Panel on Climate Change) figures, which range from 68.65 tons per TJ for gasoline to 73.27 tons per $\mathrm{TJ}$ for diesel. The average value of the electricity $\mathrm{CO}_{2}$ factor was derived from Electricity Generating Authority of Thailand (various years), based on fuel input in the electricity production sector. The energy-related $\mathrm{CO}_{2}$ emissions are given by:

$E_{t}=\sum_{i} F_{i} \times E F_{i}$ 
where $\mathrm{E}(\mathrm{t})$ is the total energy-related $\mathrm{CO}_{2}$ emissions in year $(t)$ in tones, $F_{i}$ is the consumption of fuel $i$ in year $(t)$, and $E F_{i}$ is the emission factors of fuel $i$ in year (t), which is defined as $\mathrm{CO}_{2}$ emissions per unit energy consumption by type.

Data were collected from various public sources. Some data were in electronic and excel format, while other data were in paper format. Government institutions where data were collected including the Ministry of Energy, Electricity Generating Authority of Thailand, Department of Local Administration, National Statistical Office, National Economic and Social Development Board, and Department of Land Transport. Several modifications to the original time series were conducted to calculate final energy use, as well as to estimate missing data and errors. The principal sources of historical $\mathrm{CO}_{2}$ emissions were transportation and electricity generation, both accounting for approximately $70 \%$ of the annual total $\mathrm{CO}_{2}$ emissions. The rest was contributed from solid waste, waste water, and other sources. However, historical data from these sources are not available. Furthermore, breakdowns of energy demand by sector are not available at the city level in Thailand.

\subsection{Modeling Framework: LEAP}

The LEAP end-use model was developed to estimate the future energy demand and $\mathrm{CO}_{2}$ emissions in Bangkok from 2010-2050. The model is used to analyze the impact of various energy policy interventions. The structure of the LEAP-Bangkok model is based on Phdungsilp (2010). In this paper, the model is updated with a new input dataset and the modified base year from 2000 to 2010 to be consistent with the existing energy situation, and the overall fuel balance and technology. The time horizon is extended to 2050 (the previous model horizon was from 2000 to 2025).

The LEAP model is an end-use driven scenario analysis model. It is a bottom-up model for local, national or multi-regional energy systems. LEAP has a flexible data structure when compared with top-down and other hybrid models. It is also rich in technical and end-user details (Emodi et al., 2017; Yang et al., 2017). Thus, LEAP is useful for analyzing current energy patterns and to simulate alternative energy futures, along with environmental emissions under a range of user-defined assumptions. With its links to the environmental database, LEAP can track the emissions resulting from each energy chain, including the reduction in $\mathrm{CO}_{2}$ emissions. More information regarding the LEAP modeling tool can be found in Heaps (2016).

The LEAP-Bangkok model is based on comprehensive accounting of how energy is consumed in the Bangkok geographical boundary. The demand for energy services considers four sectors, namely residential, commercial, industrial, and transportation. Each individual demand sector is disaggregated into sub-sectors, end-use, and technologies which consume and convert to energy services. End-use and energy technologies are characterized by a set of parameters, such as penetration rate, saturation share, fuel consumption, energy efficiency, energy intensity, and activity drivers.

Energy demand calculation in the LEAP-Bangkok model is based on the physical energy-consuming processes in each sector. The residential sector is disaggregated into three levels, namely high, medium, and low income classes. The number of households is taken as the base level for aggregation. The end-use level comprises of cooking, cooling, lighting, and others. The last level is the device level, which is characterized as percentage saturation and energy intensity ( $\mathrm{kWh}$ per household or toe per household). The end-use devices are disaggregated into existing appliances and high efficiency appliances. The energy intensity of each appliance is calculated from the number of appliances, capacity of appliances, and average usage hours.

The commercial sector is classified into six building types, namely office, hotel, hospital, department store, educational institution, and miscellaneous. This sector also includes large government buildings. The building database collected by the Department of Alternative Energy Development and Efficiency (DEDE), Ministry of Energy, was used to develop the energy demand model. Aggregated energy demand in the commercial sector is determined by the area of floor spaces $\left(\mathrm{m}^{2}\right)$, breakdown of annual energy consumption (airconditioning, lighting, and others), and final energy intensity $\left(\mathrm{kWh}\right.$ per $\left.\mathrm{m}^{2}\right)$. The end-use levels in each building type are space conditioning, lighting, and others.

Industrial sector is divided into nine manufacturing subsectors, according to the Thai Industrial Standard. The manufacturing industry is significantly energy intensive, accounting for more than $90 \%$ of total energy consumption in the industrial sector. The rest is 
contributed by the mining and construction industries. Industrial energy demand is formulated as a function of GPP (gross provincial product) for the industrial sector, proportion of energy utilization, estimated efficiency of energy using devices, and average useful energy intensity.

The transport sector has two categories, namely road transport and mass transit systems. Road transport is divided into sixteen vehicle types. Energy demand is calculated based on vehicle-km traveled in different vehicle types, and each type is disaggregated into existing and new technologies. Energy intensity is calculated in terms of fuel economy (liter per vehicle$\mathrm{km})$. Energy demand in mass transit systems is calculated from the load factor, average distances, and operating hours.

Projections of driver variables, such as the number of households, floor space, GPP by manufacturing subsectors, and travel demands, are determined to 2050 . The values are exogenously estimated using multiple regression analysis and the expected economic growth rate. Technical variables for example energy efficiencies of particular technologies, and shares in total activity levels, are estimated from government planning documents and extensive publications. Then the future projections of variables are supplied to the LEAP-Bangkok model.

Two main scenarios are developed to evaluate the potential of energy-savings and $\mathrm{CO}_{2}$ emission reductions, and to analyze the transition towards a lowcarbon city. These are BAU and alternative scenarios. The BAU represents an existing energy system in Bangkok. This scenario is used to examine the effects of policy interventions analyzed in the other scenario. In the alternative scenario, different policy interventions to promote low-carbon energy system are simulated by varying the trajectory of key drivers and technical variables.

\subsection{Scenario Descriptions}

\subsubsection{BAU Scenario}

BAU is a scenario for existing energy demand without policy interventions, and is a projection of what would happen in the absence of specific energy policies and strategies. The BAU scenario is composed of current accounts and future projections to 2050. The base year (2010) data set was developed from the government agencies' statistics and various reports. Demographic profiles of Bangkok are taken from the
National Statistics Office. The number of households projection was by a regression model. The share of household income classes was taken from Limmeechokchai and Chaosuangaroen (2006). Energy intensities of appliances used in the residential sector were taken from Tanatvanit et al. (2003). It is assumed that the share of efficient devices is negligible in the base year.

In the commercial sector, the projection of floor space was by the exponential growth method. Growth rates are assumed for different building types. The computation in the LEAP model is done using the GrowthAs function. Due to data limitations, this sector considers only electricity usage. The average breakdown of annual energy consumption and energy intensities are taken from Phdungsilp (2010).

The GPP of industrial sub-sectors was collected from the Office of the National Economics and Social Development Board. The projection of GPP assumed an average annual growth rate of $3 \%$. The proportions of energy utilization in end-use level and the average useful energy intensities were derived from Tanatvanit et al. (2003). These parameters are assumed to be constant during the time horizon.

Travel demand in terms of vehicle-km was estimated exogenously. The predicted numbers of vehicles were estimated using multiple regression analysis of the past number of vehicles, past and future population, and past and future expected economic growth. The average vehicle-km travelled by vehicle types was taken from published sources (for example, Tanatvanit et al., 2003). The shares of registered vehicle types were calculated from data collected by the Department of Land Transport, Ministry of Transport and Communication.

\subsubsection{Alternative Scenario}

The alternative scenario is inherited from the BAU scenario. This scenario is used for a number of "what if" questions. As the BAU scenario has been completed, an alternative scenario makes it possible for comparison. Individual policies have been created for sectors, and are then combined in sectoral combinations. The alternative scenario takes into account different policy options for energy-savings and $\mathrm{CO}_{2}$ emission reductions.

The residential sector takes into account two main policy measures, namely energy efficiency improvement and solar home generation. In the former, 
the implications of efficiency improvement of six main appliances, namely lighting equipments (fluorescent and incandescent bulb), electric heating devices (rice cooker, water heater, electric cooking appliance, and electric iron), electric motors (electric fan and washing machine), electric cooling devices (air-conditioner and refrigeration), electric loads (TV, VDO, and radio), and cooking stoves (charcoal, LPG, and wood stoves), are taken into account. It is assumed that the substitution of more efficient technologies will occur in three periods, specifically 2016-2025, 2026-2035, and 2036-2050. The penetration level of high and efficient fluorescent will replace the conventional fluorescent with rates of 25,50 , and $70 \%$ in 2016,2026 , and 2036 , respectively.

While in the case of the incandescent bulb, compact fluorescent will replace the incandescent bulb with rates of 40,60 , and $70 \%$ in the same periods. For other measures, each device has two different efficiency improvements (efficient 1 and 2). In the first, second, and third periods, the efficient 2 device, which has higher efficiency improvement than the efficient 1 device, will substitute the conventional one and increase the shares until all household devices have efficient devices. In the case of a water heater, it is considered only in the high income class. Cases of charcoal and wood stove are considered for the middle and low income classes. For the solar home generation or $1 \mathrm{~kW}$ solar home policy, it is assumed that each household will generate electricity through solar energy technology, with capacity of $1 \mathrm{~kW}$ per household, which results in the reduction of electricity use in each household. The penetration levels of solar homes will be $30 \%$ by 2020 and $50 \%$ by 2030 .

The commercial sector considers the electricity used in air-conditioning, lighting equipments, and electric appliances due to a high proportion of energy consumption in buildings. The proposed policy interventions aim for efficiency improvement. These policies are lighting power density, equipment power density, shading coefficient of window, thermal conductance of window, thermal conductance of wall, improving chiller's COP (coefficient of performance), and window-to-wall ratio. The first intervention aims to improve energy efficiency of the lighting system, while the second considers efficient appliances. The rest is mainly for cooling load reduction. The improved energy intensities in all policy interventions will start in 2010. The technical data for breakdown energy consumption and potential electricity reduction are based on DEDE building database. The remaining data are the same as in the BAU scenario.

There are two policy interventions in the industrial sector. In the first, it is assumed that all manufacturing sub-sectors will switch to natural gas, according to the Thai government policy to promote the use of natural gas. The fuel switching takes place in thermal energy supplied by non-renewable resources such as fuel oil and diesel. This intervention takes effect in 2011. By the end of the period, thermal energy demand supplied by non-renewable resource will be replaced by natural gas. The second intervention assumes that industry in Bangkok meets a $10 \%$ improvement in energy efficiency, beginning in 2010 and useful energy efficiency improving linearly until 2050. The efficiency improvements occur in lighting, compressed air, motor, boiler, and steam system efficiency.

The transport sector focuses on land transport only. Policy interventions involve behavioral changes (switching to mass transit systems), use of cleaner fuels (natural gas vehicle, bio-diesel, and gasohol), technological changes (hybrid electric car), and fuel economy improvement. The public transportation improvement policy considers the existing plans of mass transit systems. Numbers of passengers who shift from road transport to mass transit systems are assumed to be 10,30 , and $40 \%$ in 2010,2020 and 2030, respectively, and only sedan cars are considered. The electricity demand for mass transit systems is estimated by the total load demand of each mass transit project. Fuel switching policy includes a shift from higher carbon content to lower carbon content fuels. These shifts apply to natural gas, biodiesel and gasohol.

Natural gas vehicle (NGV) considers the substitution of bi-fuel engine for spark ignition engine, such as in sedan cars and urban taxis, and the substitution of compressed natural gas (CNG) dedicated engine for compression ignition engine, such as fixed-route buses, and vans and pick-ups. It also assumes an increase in the use of NGV by $50 \%$ in 2050. Bio-diesel and gasohol policies are based on Thai government policies to promote the substitution of bio-diesel in diesel engine and the use of gasohol in gasoline engines.

The hybrid electric sedan policy assumes that hybrid cars will be substituted for new conventional sedan cars with a market penetration of $15 \%$ of new sedans saturated in 2015. It is also assumed to 
increase the penetration rate to $30 \%$ in 2030 . The fuel economy improvement policy is based on the implementation of the minimum fuel economy standard program to reduce energy demand and associated emissions by the government. The fuel economy of gasoline sedans and diesel pick-ups should exceed the minimum fuel economy standards of 6.9013 and 5.8608 liter per vehicle-km travelled, respectively.

\section{RESULTS}

\subsection{Historical Trends}

Owing to unavailable data in the disaggregated sector, the historical trends of energy demand and energy-related $\mathrm{CO}_{2}$ emissions were calculated from petroleum products and electricity consumption. Energy demand and associated $\mathrm{CO}_{2}$ emissions by fuel types (gasoline, diesel, LPG, fuel oil, and electricity) are shown in Figure 1. From 1950 to 2010, total energy use increased at compound annual growth rate (CAGR) of $0.03 \%$, which means it rose from 2,630 ktoe in 1950 to $15,582 \mathrm{ktoe}$ in 2010. During the same period, the population in Bangkok increased from 1.3 million to almost 6 million. In terms of energy use per capita, energy consumption increased from 2.031 to 2.597 toe per capita from 1950 to 2010 .

With the rising energy demand, the total $\mathrm{CO}_{2}$ emissions from energy use have increased from 8.0 Mt- $\mathrm{CO}_{2}$ in 1950 to $64.8 \mathrm{Mt}-\mathrm{CO}_{2}$ in 2010, with a CAGR of $0.04 \%$ (Figure 1). One of the reasons behind the increased $\mathrm{CO}_{2}$ emissions was the rapid increase in the number of vehicles, and economic development in Bangkok. Vehicle stocks have increased greatly during the period, so $\mathrm{CO}_{2}$ emissions from the transport sector contributed a large share of total emissions. A detailed breakdown of energy consumption data were not available, so it is not possible to compare this with other sectors.

\subsection{Future Energy Demand and $\mathrm{CO}_{2}$ Emissions in Bangkok}

\subsubsection{BAU Scenario}

The BAU scenario continues past trends, and no specific policy interventions to existing trends are implemented. The results show that energy demand in Bangkok will increase dramatically, reaching 54,560 ktoe in 2050. It is estimated to be about four times that of the base year (2010). Per capita energy demand in Bangkok is expected to be 7.26 toe per capita in 2050 . Estimated breakdowns of energy demand by sectors in 2050 are industrial (51\%), transport $(44 \%)$, and residential and commercial (5\%). Fossil fuels still dominate energy sources in Bangkok, and the shares of gasoline, diesel, electricity, and natural gas in total energy demand for 2050 are estimated to be $29 \%$, $16 \%, 13 \%$, and $4 \%$, respectively. The rest is contributed to other fossil fuels, such as coal and lignite. The share of renewable energy sources are expected to contribute about $14 \%$ in 2050 (Figure 2 and Table 1).

The total $\mathrm{CO}_{2}$ emissions (non-biogenic) in 2010 were $64.85 \mathrm{Mt}^{-\mathrm{CO}_{2}}$ under the $\mathrm{BAU}$ scenario. These amounts will increase to $190.88 \mathrm{Mt}-\mathrm{CO}_{2}$ in 2050 , as shown in Table 1. $\mathrm{CO}_{2}$ factors in this pare are taken directly from the LEAP database, which are based on IPCC guidelines for national GHG inventories. At the

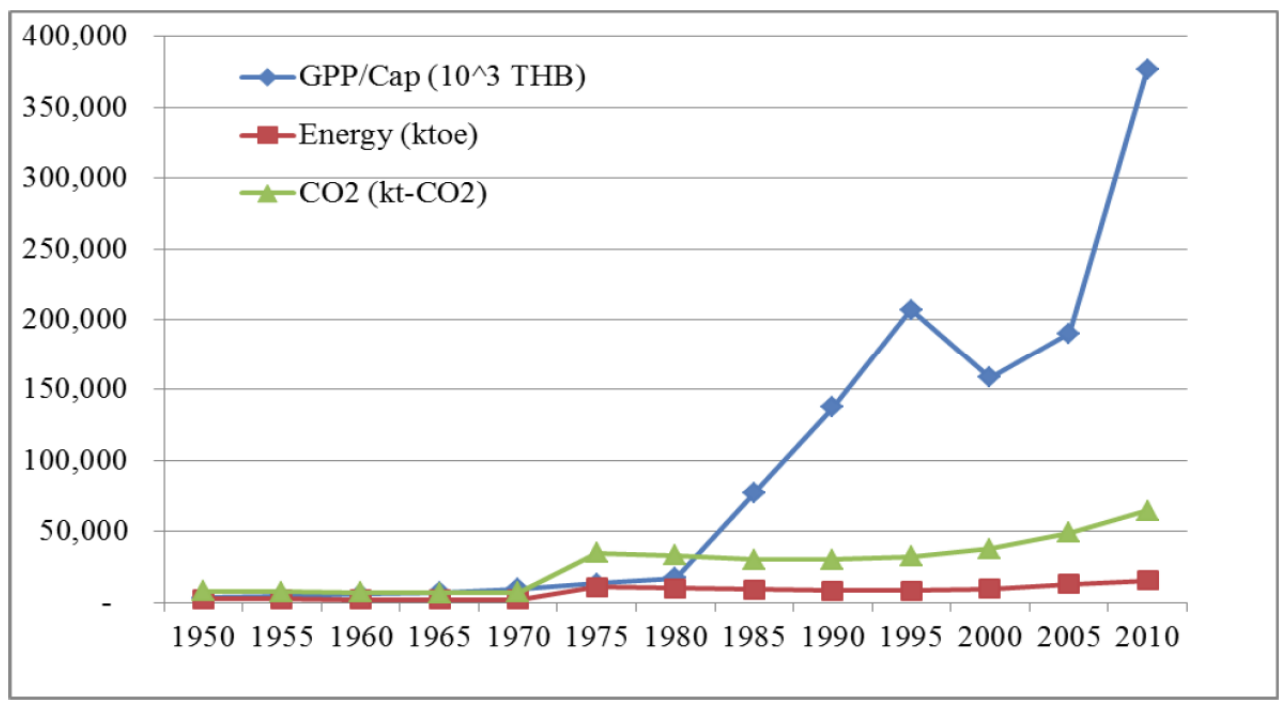

Figure 1: Historical trends of energy demand and $\mathrm{CO}_{2}$ emissions from 1950 to 2010. 


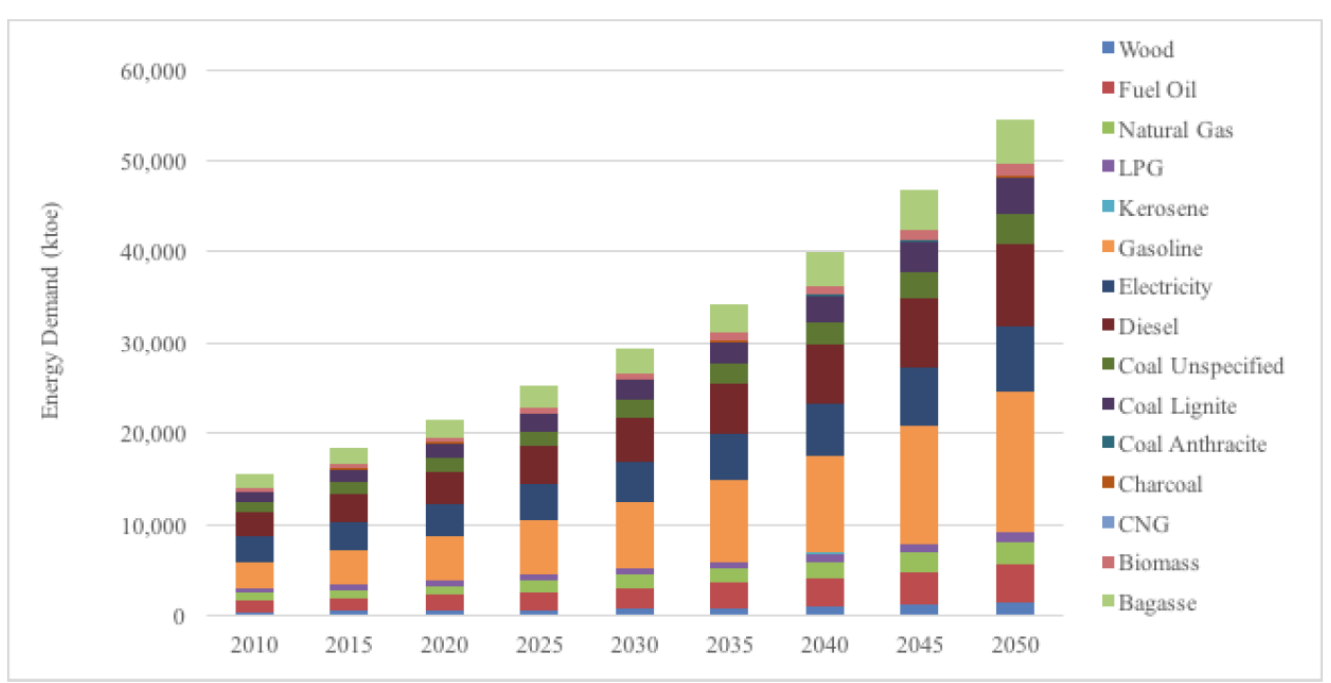

Figure 2: Energy demand in Bangkok by fuel types in the BAU scenario.

Table 1: Energy Demand and $\mathrm{CO}_{2}$ Emissions in Bangkok under the BAU Scenario

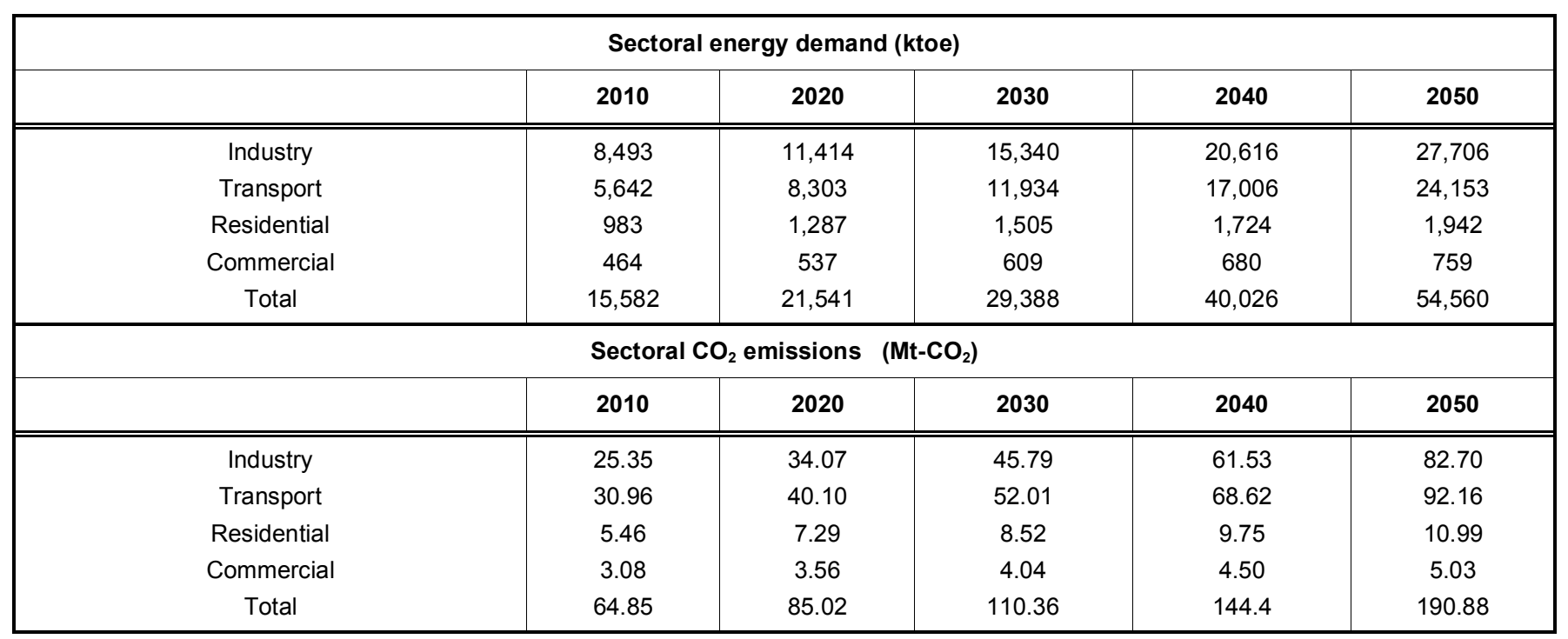

sectoral level, the findings show that the industrial and transport sectors are the main contributors to energy demand and $\mathrm{CO}_{2}$ emissions. This reflects on the economic structure in Bangkok, and depends on road transportation. Table 1 illustrates the final energy demand and $\mathrm{CO}_{2}$ emissions by sectors in Bangkok from 2010 to 2050 .

The industrial energy demand accounts for around $40 \%$ of total energy demand in Bangkok. This sector will continue to remain the most energy intensive sector through 2050. Industrial sub-sectors with high energy demand, such as food and beverages and non-metallic industries, make up over $60 \%$ of total industrial demand (see Figure 3a). The modeling results indicate that the final energy demand in the industrial sector will increase from 8,493 ktoe in 2010 to 27,706 ktoe in
2050. $\mathrm{CO}_{2}$ emissions will rise from $25.35 \mathrm{Mt}-\mathrm{CO}_{2}$ to $82.70 \mathrm{Mt}-\mathrm{CO}_{2}$ during the same period.

Transportation is the second largest energyconsuming sector. Energy demand is expected to grow over time. This is reflected in the modeling results that final energy demand of this sector will increase from 535 ktoe in 2010 to 1,745 ktoe in 2050. Transport energy demand is dominated by road transport, which accounts for more than $95 \%$, while the remainder is for mass transit systems (Figure $\mathbf{3 b}$ ). Road transport, which comprises sixteen vehicle types, sedan cars and vans and pick-ups account for about $60 \%$ of total transport energy demand. Total emissions increase from $30.96 \mathrm{Mt}-\mathrm{CO}_{2}$ in 2010 to $92.16 \mathrm{Mt}-\mathrm{CO}_{2}$ in 2050 . The contribution from the transport sector becomes more dominant in the future. The reason is that the 
projection of the road transport demand increases, and is motivated by expected economic growth and poor mass transit systems.

Residential energy demand is expected to reach 1,942 ktoe in 2050. Energy demand of the residential sector is mainly for cooling purposes (Figure 3c). $\mathrm{CO}_{2}$ emissions are estimated to be $11 \mathrm{Mt}-\mathrm{CO}_{2}$ in 2050, or about twice that in the base year. In all income classes, the results show that cooling demand is the largest share of energy use in this sector, followed by cooking, electric devices, and lighting, respectively. Demand for cooling will grow rapidly in the new development residential buildings as indoor comfort becomes more of a priority, as well as the rise in income.

Energy demand in the commercial sector includes both commercial buildings and large governmental buildings. The modeling considers only the use of electricity in all building types due to the data unavailable of other energy sources. In 2010, building energy consumption was comprised entirely of electricity 464 ktoe, while in 2050 it will rise to 759 ktoe (Figure 3d). In all building types, air-conditioning shows

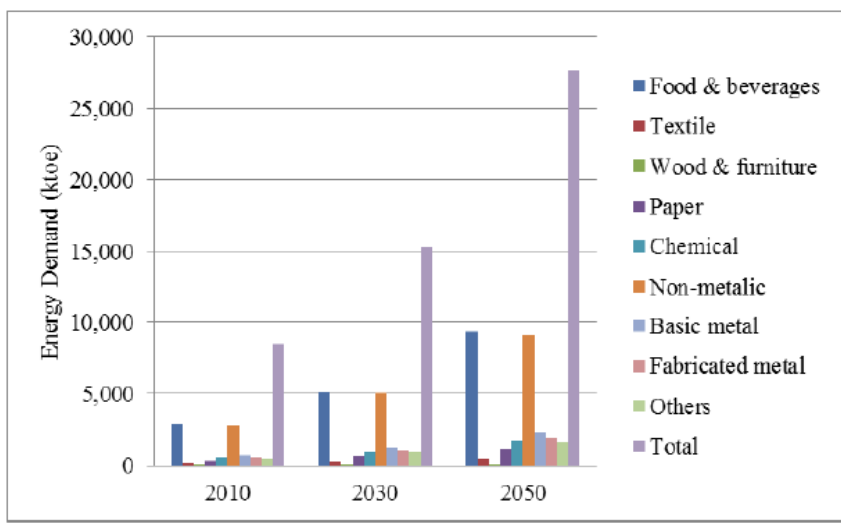

(a) Industrial energy demand

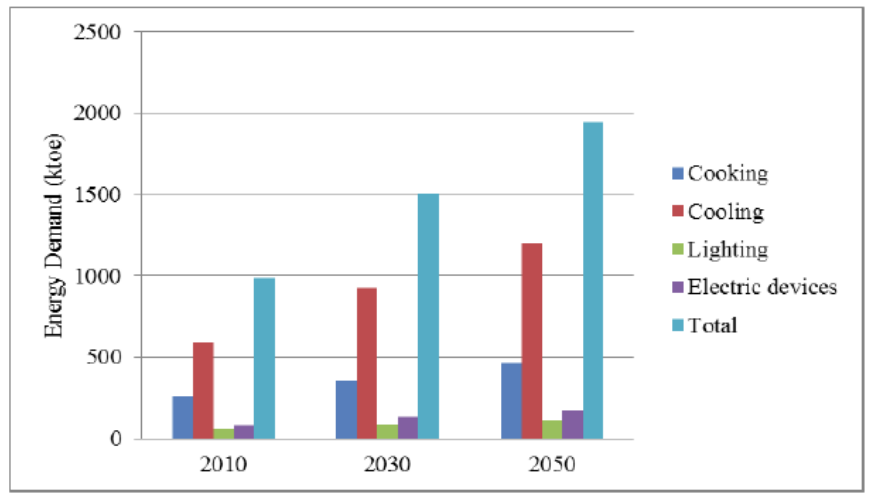

(c) Residential energy demand the largest share of building energy use, expanding from 253 ktoe to 407 ktoe between 2010 and 2050 . Electricity use for lighting and other purposes rises more slowly. As a result, $\mathrm{CO}_{2}$ emissions for 2050 are estimated as twice as high compared with the base year.

\subsubsection{Implications of Alternative Scenario}

The alternative scenario is compared to the BAU scenario for assessing the potential for energy-savings and $\mathrm{CO}_{2}$ emission reductions. This scenario compares the results of various policy interventions from the viewpoint of reduced energy demand and emissions under various policy interventions (see Table 2).

The results of scenario analysis show that if all policy interventions are implemented simultaneously, the potential for energy-savings in 2030 and 2050 are estimated to be 15,787 ktoe and 32,120 ktoe, respectively. The corresponding figures in reduced $\mathrm{CO}_{2}$ emissions are expected to be $52.34 \mathrm{Mt}-\mathrm{CO}_{2}$ and $106.19 \mathrm{Mt}-\mathrm{CO}_{2}$ for the same years. Figure 4 shows per capita energy use and $\mathrm{CO}_{2}$ emissions in $\mathrm{BAU}$ and alternative scenarios. The alternative scenario shows

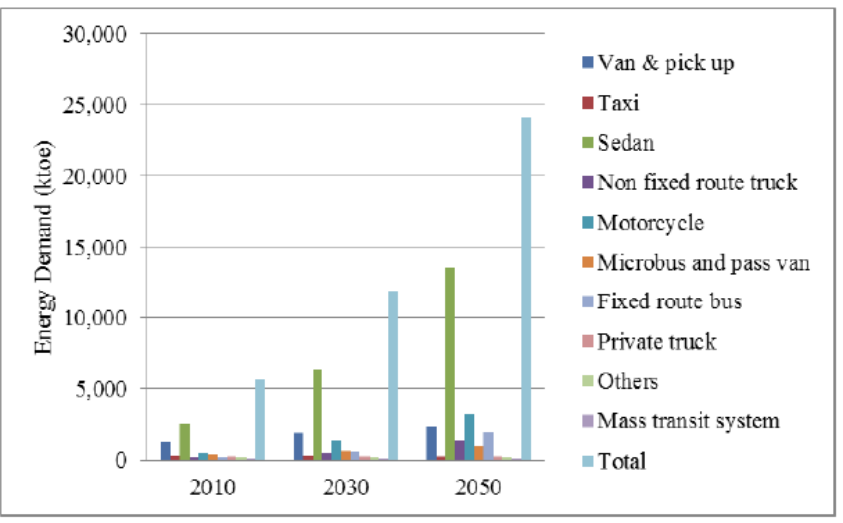

(b) Transport energy demand

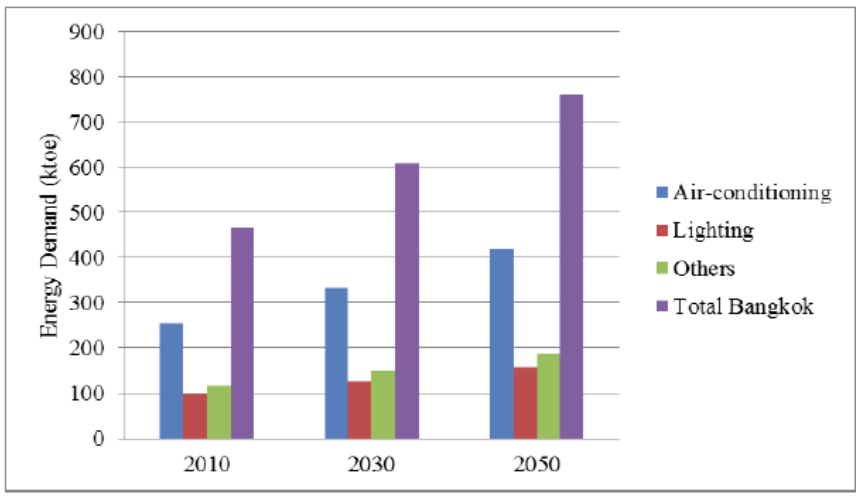

(d) Commercial energy demand

Figure 3: End-use energy demand in different sectors in Bangkok. 
Table 2: Reduction Potential for Energy Use by Policy Interventions (ktoe)

\begin{tabular}{|c|c|c|}
\hline Policy interventions & 2030 & 2050 \\
\hline \multicolumn{3}{|c|}{ Residential sector } \\
\hline Energy efficiency improvement & 1,557 & 1,996 \\
\hline Solar home generation & 1,282 & 1,653 \\
\hline \multicolumn{3}{|c|}{ Commercial sector } \\
\hline Lighting power density & 96 & 119 \\
\hline Equipment power density & 108 & 134 \\
\hline Shading coefficient of window & 305 & 377 \\
\hline Window-to-wall ratio & 316 & 391 \\
\hline Thermal conductance of wall & 270 & 334 \\
\hline Thermal conductance of window & 318 & 393 \\
\hline Improving chiller's COP & 250 & 309 \\
\hline \multicolumn{3}{|c|}{ Industrial sector } \\
\hline $10 \%$ improvement in energy efficiency & 1,534 & 2,771 \\
\hline Switching to natural gas & 45 & 81 \\
\hline \multicolumn{3}{|c|}{ Transport sector } \\
\hline Switching to mass transit system & 4,494 & 9,116 \\
\hline Natural gas vehicle & 2,032 & 7,722 \\
\hline Fuel economy improvement & 1,445 & 2,765 \\
\hline Hybrid sedan car & 862 & 1,836 \\
\hline Bio-diesel & 319 & 777 \\
\hline Gasohol & 554 & 1,346 \\
\hline
\end{tabular}

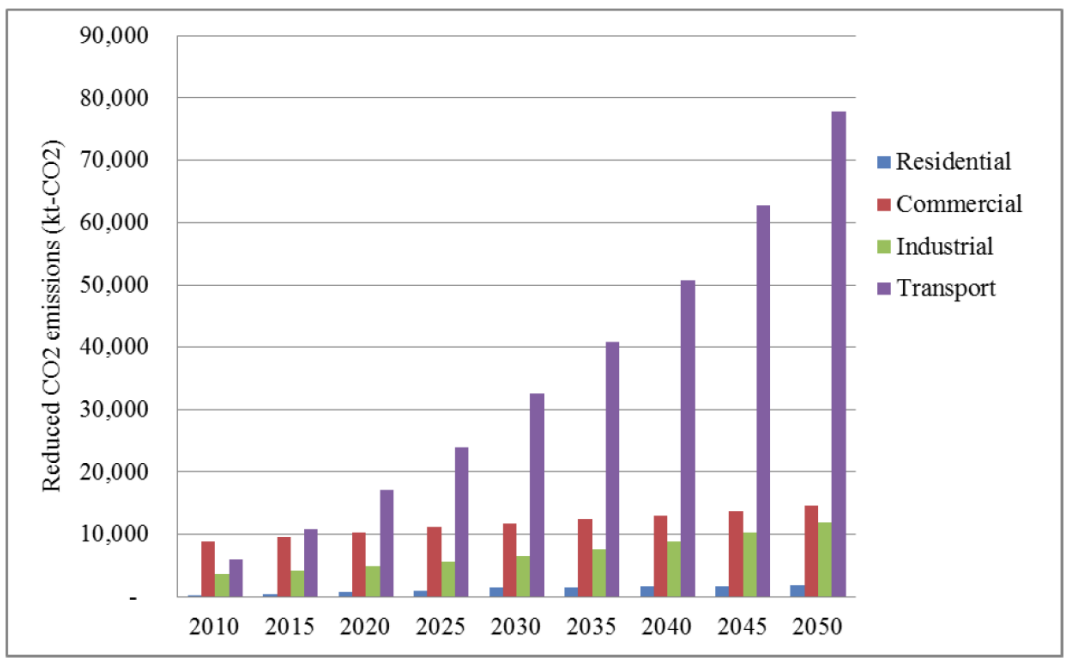

Figure 4: Reduced $\mathrm{CO}_{2}$ emissions in the alternative scenario by sector.

the technical possibilities to slow the growth of both energy demand and $\mathrm{CO}_{2}$ emissions.

\section{CONCLUSION}

This paper presented the historical trends of energy demand and energy-related $\mathrm{CO}_{2}$ emissions in Bangkok from 1950 to 2010 . It was found that energy demand increased from 2,630 ktoe to $15,582 \mathrm{ktoe}$, and $\mathrm{CO}_{2}$ emissions from energy use increased from $8.0 \mathrm{Mt}-\mathrm{CO}_{2}$ to $64.8 \mathrm{Mt}-\mathrm{CO}_{2}$. The paper applied the LEAP-Bangkok model to projections of energy use and $\mathrm{CO}_{2}$ emissions, and analyzed alternative policy interventions.

Two scenarios were formulated to simulate energy demand and $\mathrm{CO}_{2}$ emissions in four sectors from 2010 to 2050. The BAU scenario represented existing energy demand without policy interventions. The 
alternative scenario took into account different policy interventions for energy-savings and $\mathrm{CO}_{2}$ emission reductions. The results showed that, under the BAU scenario, total energy demand would increase dramatically, reaching 54,560 ktoe in 2050 and result in $191 \mathrm{Mt}-\mathrm{CO}_{2}$ emissions.

Under the alternative scenario, if all policy interventions were implemented simultaneously, the potential for energy-savings and reduced $\mathrm{CO}_{2}$ emissions in 2050 were estimated to be 32,120 ktoe and $106.19 \mathrm{Mt}-\mathrm{CO}_{2}$, respectively. It is clear that the industrial and transport sectors are the main energy consumer and emitter sectors. This requires more aggressive policies and measures if Bangkok is to develop appropriate strategies to become a low-carbon city in the future.

\section{ACKNOWLEDGEMENT}

The author wishes to acknowledge helpful comments and suggestions from Chia-Lin Chang and Michael McAleer.

\section{REFERENCES}

Allen, C., Metternicht, G., Wiedmann, T. (2016), National pathways to the Sustainable Development Goals (SDGs): A comparative review of scenario modelling tools, Environmental Science \& Policy, 66, 199-207. https://doi.org/10.1016/j.envsci.2016.09.008

Emodi, N.V., Emodi, C.C., Murthy, G.P., Emodi, A.S.A. (2017), Energy policy for low carbon development in Nigeria: A LEAP model application, Renewable and Sustainable Energy Reviews, 68, 247-261.

https://doi.org/10.1016/j.rser.2016.09.118

Ghanadan, J., Koomey, G. (2005), Using energy scenarios to explore alternative energy pathways in California, Energy Policy, 33, 1117-1142. https://doi.org/10.1016/j.enpol.2003.11.011

Heaps, C.G. (2016). Long-range Energy Alternatives Planning (LEAP) system. Stockholm Environment Institute, Somerville, MA, USA. https://www.energycommunity.org

Huang, Z., Yu, H., Peng, Z., Zhao, M. (2015), Methods and tools for community energy planning: A review, Renewable and Sustainable Energy Reviews, 42, 1335-1348. https://doi.org/10.1016/..rser.2014.11.042

Kadian, R., Dahiya, R.P., Garg, H.P. (2007), Energy-related emissions and mitigation opportunities from the household sector in Delhi, Energy Policy, 35, 6195-6211. https://doi.org/10.1016/j.enpol.2007.07.014

Lazarus, M., Chandler, C., Erickson, P. (2013), A core framework and scenario for deep GHG reductions at the city scale,
Energy Policy, 57, 563-574.

https://doi.org/10.1016/j.enpol.2013.02.031

Limmeechokchai, B., Chaosuangaroen, P. Assessment of energy saving potential in the Thai residientail sector: Long-range Energy Alternative Planning approach. In: Proceedings of the 2nd Joint International Conference on Sustainable Energy and Environment (SEE 2006): Bangkok, Thailand, 21-23 November 2006.

Lind, A., Espegren, K. (2017), The use of energy system models for analysing the transition to low-carbon cities-The case of Oslo, Energy Strategy Reviews, 15, 44-56. https://doi.org/10.1016/j.esr.2017.01.001

Markovic, D., Cvetkovic, D., Masic, B. (2011), Survey of software tools for energy efficiency in a community, Renewable and Sustainable Energy Reviews, 15, 4897-4903. https://doi.org/10.1016/j.rser.2011.06.014

Martínez-Jaramillo, J.E., Arango-Aramburo, S., Álvarez-Uribe, K.C., Jaramillo-Álvarez, P. (2017), Assessing the impacts of transport policies through energy system simulation: The case of the Medellin Metropolitan Area, Colombia, Energy Policy, 101, 101-108. https://doi.org/10.1016/j.enpol.2016.11.026

Peng, B., Du, H., Ma, S., Fan, Y., Broadstock, D.C. (2015), Urban passenger transport energy saving and emission reduction potential: A case study for Tianjin, China, Energy Conversion and Management, 102, 4-16.

https://doi.org/10.1016/j.enconman.2015.01.017

Phdungsilp, A. (2010), Integrated energy and carbon modeling with a decision support system: Policy scenarios for low-carbon city development in Bangkok, Energy Policy, 38, 4808-4817. https://doi.org/10.1016/j.enpol.2009.10.026

Phdungsilp, A. (2015), Modeling urban energy flows at macro and district Levels, Doctoral Thesis, Department of Civil and Architectural Engineering, KTH Royal Institute of Technology, Stockholm, Sweden.

Rinchumpoo, D. (2005), Energy-environmental analysis of alternative transport scenarios: Case of Greater Bangkok Region, Asian Institute of Technology, Pathumthani, Thailand.

Tanatvanit, S., Limmeechokchai, B., Chungpaibulpatana, S. (2003) Sustainable energy development strategies: Implications of energy demand management and renewable energy in Thailand, Renewable and Sustainable Energy Reviews, 7, 367-395.

https://doi.org/10.1016/S1364-0321(03)00066-2

Winkler, H., Borchers, M., Hughes, A., Visage, E., Heinrich, G. (2005), Cape Town Energy Futures: Policies and Scenarios for Sustainable City Energy Development, Energy Research Centre, University of Cape Town, Cape Town, South Africa. (http:www.energycommunity.org/documents/CapeTownEner gy.pdf).

Yang, D., Liu, B., Ma, W., Guo, Q., Li, F., Yang, D. (2017), Sectoral energy-carbon nexus and low-carbon policy alternatives: A case study of Ningbo, China, Journal of Cleaner Production, $156,480-490$ https://doi.org/10.1016/j.jclepro.2017.04.068

Zhao, G., Guerrero, J.M., Jiang, K., Chen, S. (2017), Energy modelling towards low carbon development of Beijing in 2030, Energy, 121, 107-113.

https://doi.org/10.1016/j.energy.2017.01.019

\section{DOI: https://doi.org/10.6000/1929-7092.2017.06.24}

() 2017 Aumnad Phdungsilp; Licensee Lifescience Global.

This is an open access article licensed under the terms of the Creative Commons Attribution Non-Commercial License (http://creativecommons.org/licenses/by-nc/3.0/) which permits unrestricted, non-commercial use, distribution and reproduction in any medium, provided the work is properly cited. 